\title{
A survey of the hybridisation status of Cervus deer species on the island of Ireland
}

\author{
Stephanie L. Smith $\cdot$ Ruth F. Carden • \\ Barry Coad $\cdot$ Timothy Birkitt $\cdot$ Josephine M. Pemberton
}

Received: 15 September 2013/Accepted: 5 February 2014/Published online: 1 March 2014

(C) The Author(s) 2014. This article is published with open access at Springerlink.com

\begin{abstract}
Red deer (Cervus elaphus) did not recolonise Ireland after the last glaciation, but the population in Co. Kerry is descended from an ancient (c. 5000 BP) introduction and merits conservation. During the mid-19th century exotic species including North American wapiti $(C$. canadensis) and Japanese sika deer (C. nippon nippon) were introduced to Ireland, mainly via Powerscourt Park, Co. Wicklow. While wapiti failed to establish, sika thrived, dispersed within Co. Wicklow and were translocated to other sites throughout Ireland. Red deer and sika are known to have hybridised in Ireland, particularly in Co. Wicklow, but an extensive survey with a large, highly diagnostic marker panel is required to assess the threat hybridisation potentially poses to the Co. Kerry red deer population. Here, 374 individuals were genotyped at a panel of 22 microsatellites and at a single mtDNA marker that are highly diagnostic for red deer and Japanese sika. The microsatellites are also moderately diagnostic for red deer and wapiti. Wapiti introgression was very low [trace evidence in $2(0.53 \%)$ individuals]. Despite long-standing
\end{abstract}

Electronic supplementary material The online version of this article (doi:10.1007/s10592-014-0582-3) contains supplementary material, which is available to authorized users.

\section{S. L. Smith · J. M. Pemberton}

Institute of Evolutionary Biology, School of Biological Sciences,

University of Edinburgh, Edinburgh EH9 3JT, UK

S. L. Smith $(\bowtie)$

SRUC, Roslin Institute Building, Easter Bush,

Midlothian EH25 9RG, UK

e-mail: Stephanie.Smith@sruc.ac.uk

R. F. Carden

Natural History Division, National Museum of Ireland, Merrion

Street, Dublin 2, Ireland sympatry of red deer and sika in the area, no red deer-sika hybrids were detected in Co. Kerry suggesting strong assortative mating by both species in this area. However, 80/197 (41 \%) of deer sampled in Co. Wicklow and 7/15 $(47 \%)$ of deer sampled in Co. Cork were red-sika hybrids. Given their proximity and that hybrids are less likely to mate assortatively than pure individuals, the Co. Cork hybrids pose a threat to the Co. Kerry red deer.

Keywords Microsatellite $\cdot$ Hybridisation - Introgression · mtDNA $\cdot$ Sika $\cdot$ Red deer

\section{Introduction}

Hybridisation is the interbreeding of genetically distinct taxa, while introgression is the resultant horizontal gene flow between hybridising taxa (Allendorf et al. 2001). Hybridisation occurs naturally in perhaps $25 \%$ of plant and $10 \%$ of animals species, where it is a natural source of new genetic variation (Mallet 2005). However, through hunting, habitat degradation, domestication and translocation, humans have brought many non-native species into

\section{R. F. Carden}

School of Biological, Environmental and Earth Sciences, University College Cork, Distillery Fields, North Mall, Cork, Ireland

B. Coad

Research and Environment, Coillte, Saville House, Rathdrum, Co. Wicklow, Ireland

T. Birkitt

National Parks and Wildlife Service, Killarney, Co. Kerry, Ireland 
contact with native heterospecifics, leading to anthropogenically induced hybridisation, which can have various adverse consequences. The generation of hybrids between an invasive and a native species without introgression (e.g. due to strong selection against F1 hybrids) can result in substantial wasted reproduction, exemplified by the generation of sterile hybrids between the native bull trout (Salvelinus confluetus) and the introduced brook trout ( $S$. fontinalis) in North America, leading to the displacement of the former species (Leary et al. 1993). If introgression does occur, it can be highly destructive to the integrity of locally adapted species, races or ecotypes, potentially leading to their extinction (Allendorf et al. 2001). Examples include introgression between three fur seal species (Arctocephalus gazelle, A. tropicalis and A. forsterri) during recolonisation of Macquarie Island after seal harvesting eliminated the original population (Lancaster et al. 2006), interbreeding between endemic mouse lemur species in southern Madagascar (Microcebus spp.) where deforestation and acidification has facilitated asymmetric gene flow due to the expansion of the dry spiny forest ecotone (Gligor et al. 2009), and the introgression of maladaptive gene complexes into wild American mink (Neovison vison) from escaped farmed American mink, causing population decline (Kidd et al. 2009).

Deer species of the genus Cervus have been extensively translocated around the world for hunting, farming or ornamental purposes and are prone to hybridisation (Whitehead 1964; Ratcliffe 1987). In contrast to its current global presence, the genus has a mainly Holartic natural distribution (Ludt et al. 2004). Mitochondrial sequence information suggests the point at which the group containing red deer, wapiti and sika occurred $~ 3.5$ MYA around Kyrgyzstan, following the innovative appearance of the ' 4 point' antler structure in the early/middle Pliocene (Di Stefano and Petronio 2002; Pitra 2005; Ludt et al. 2004). From there a western-migrating clade became the medium-sized red deer (Cervus elaphus) whilst those moving east bifurcated into the larger wapiti (including the North American C. canadensis) and smaller sika which itself diversified (c. 2MYA) throughout south-eastern Asia including in Japan ( $C$. nippon nippon), China (C. $n$. mantchuricus) and Taiwan (C. n. taiouanus) (Cook et al. 1999; Kuwayama and Ozawa 2000; Pitra 2005; Ludt et al. 2004). Another clade diversified into the Asian sambar (Rusa unicolor) and its allies (Ludt et al. 2004; Huang et al. 2006). Despite red deer and sika sitting at opposite ends of the Cervus distribution, having substantial mitochondrial genetic divergence, a difference of two Robertsonian translocations between their karyotypes and large morphological differences (Table 1 in Senn and Pemberton 2009), they are able to hybridise in captivity and in the wild (Harrington 1973; Huang et al. 2006; Lowe and Gardiner
1975; Goodman et al. 1999; Senn and Pemberton 2009). Similarly, despite a large size difference, red deer and wapiti have hybridised in the wild in Fiordland, New Zealand (Shackell et al. 2003) and in captivity, which has been exploited on New Zealand deer farms (Moore and Littlejohn 1989; Shackell et al. 2003). Several other hybridisations between genus Cervus deer have also been observed, including sambar-red deer (Powerscourt 1884; Gray 1971).

Hybridisation between Cervus deer of different species has substantial phenotypic consequences, which are likely to alter their ecology and complicate management. In a wild red-sika hybrid zone in Kintyre, Argyll (Scotland), following genetic analysis, the proportion of red deer ancestry was estimated ('Q', see Methods) and its influence on carcass traits was analysed (Senn et al. 2010). Carcass weight, jaw length and incisor arcade breadth were all linearly related to Q, i.e. the more red deer genome present, the larger the individual (Senn et al. 2010). On New Zealand deer farms which predominantly farm red deer, wapiti have been deliberately hybridised and introgressed to increase carcass and antler size of red deer (Moore and Littlejohn 1989). These points indicate that there is substantial additive genetic variation for quantitative traits in hybrid deer and that detection of advanced backcrosses from phenotype alone is likely to be hard, making selective culling of introgressed individuals difficult.

In Ireland, red deer were present in the last interglacial period but did not return after the last glaciation (the Younger Dryas). The modern red deer population is descended from ancient and recent postglacial introductions by man (Carden et al. 2012). Currently, there are around 4,000 phenotypically red deer in Ireland (Pérez-Espona et al. 2009a). They are primarily present in the East (Co. Wicklow), the South West (Co. Kerry) and the North West (Co. Galway north to Co. Donegal) and have shown a $6.5 \%$ range expansion from these sites over the last 30 years (Whitehead 1964; Carden et al. 2011). Recent work has established that the red deer centred on Killarney, Co. Kerry, are descended from a human introduction from Britain during the Neolithic period (Carden et al. 2012). The other populations are descended from more recent introductions from Britain and continental Europe, in several cases indirectly through deer parks, primarily Powerscourt Park, Co. Wicklow, where they may have interacted with other Cervus species (McDevitt et al. 2009; Carden et al. 2012). The Co. Kerry red deer population has also been involved in more recent documented translocations as both donor and recipient (Whitehead 1960, 1964; Carden et al. 2011).

Japanese sika were introduced to Powerscourt Park in 1860. Although only one male and three females were introduced, they successfully established and by 1884 there were over 100 sika in the Park, despite culling and 
translocation to other counties (Powerscourt 1884). In the same year Viscount Powerscourt reported three or four animals that were 'certainly hybrid' between red deer and Japanese sika in his park, with the red deer in each case being the dam (Powerscourt 1884). By the 1930s red deer and sika thrived outside the overcrowded conditions of Powerscourt Park and the males competed successfully when they returned for the rut (Delap 1936; Whitehead 1964) though the extent to which the population included hybrids is unclear. Based on phenotype, it has been apparent for many years that the wild Co. Wicklow deer population contains substantial numbers of red-sika hybrids and these likely originated from Powerscourt during disturbances in 1922 (Harrington 1973; Whitehead 1964). Harrington (1973) reported around 250 hybrid animals across Co. Wicklow within a wild population of around 3,000 sika-like individuals. From Powerscourt, sika were translocated elsewhere, including a very early translocation to Co. Kerry in 1864 (McDevitt et al. 2009) and to various other sites in Ireland and the UK (Ratcliffe 1987). Over the last 30 years, this invasive species has expanded its range at around $5 \%$ per annum from populations in the East, South West and North West of Ireland (Carden et al. 2011). The extent of hybridisation in the North West has not been well studied, and the presence of red-sika hybrids in this region is suspected (Harrington 1973; Pérez-Espona et al. 2009a; Carden et al. 2011) but there is no definitive evidence of it to date. Despite a long period of sympatry (1864 to present), no phenotypic hybrids have been reported in Co. Kerry. However, the above expansion rates highlight the risk that already-hybridised animals from the other parts of Ireland may spread into Co. Kerry and threaten the genetic integrity of the red deer in this area (Pérez-Espona et al. 2008; Carden et al. 2011).

At least three other exotic subspecies or species of the genus Cervus have also been introduced to Ireland, largely through the activities of Viscount Powerscourt (Powerscourt 1884). In 1865 two male and one female North American wapiti were introduced to Powerscourt and towards the end of the 1800s a single wapiti female was introduced to Co. Tyrone (Whitehead 1964). Whilst reports suggest there were up to five wapiti individuals at Powerscourt, around 1880 these animals had been disposed of (Powerscourt 1884; Whitehead 1964) and we are not aware of reports of hybrids between red deer and wapiti in Ireland. A second sika subspecies, Manchurian sika (C. $n$. mantchuricus) was introduced, is now free living in Co. Mayo and may have been supplemented by further translocations (McDevitt et al. 2009). Despite little information surrounding the actual introduction to Powerscourt Park, there is mention of hybrids between Manchurian sika and the red deer in the park and the fate of these animals is unknown (Powerscourt 1884; Ratcliffe 1987; McDevitt et al. 2009). Red-Manchurian sika hybrids were also suspected in Co. Fermanagh between 1885 and 1891 (Whitehead 1964). Lastly, sambar deer were also introduced around the mid-19th century to Powerscourt (Powerscourt 1884). Hybrids between red deer and sambar were reported in Powerscourt, but are believed to have died out (Powerscourt 1884). The deer park at Powerscourt was disbanded by 1960 , when it is believed poachers broke down the perimeter walls and the deer escaped (Powerscourt Park staff, pers. comm.).

Two previous studies have investigated hybridisation between red deer and Japanese sika in Ireland using genetic techniques. Using rocket immuno-electrophoresis of serum proteins, Harrington (1973, 1979), suggested there were no pure deer of either species in Co. Wicklow but no hybrids in Co. Kerry. While potentially very sensitive, this method does not allow straightforward quantification of the extent of introgression of an individual. Using eight microsatellite markers (of which three overlap with the present study and are diagnostic for red deer and Japanese sika) and analysis using the Bayesian clustering software package Structure (Pritchard et al. 2000), McDevitt et al. (2009) analysed 132 deer from around Ireland. This study suggested that while Co. Kerry and Co. Down harboured only pure red deer and pure sika, deer in other areas included hybrids, and specifically that the Co. Wicklow population included pure red deer, pure sika and hybrids (McDevitt et al. 2009). In Co. Wicklow, these authors also noted that hybrids were found amongst both phenotypically red deer and sika individuals and that sika-like individuals (based on phenotype and genotype) sometimes had red deer mitochondrial DNA.

Taken overall, concern has grown as to the extent and consequences of hybridisation and introgression among deer, particularly between red deer and Japanese sika, in Ireland. Hybrid swarms, such as that previously documented in Co. Wicklow, may exist undetected elsewhere on the island of Ireland where these species overlap and could be expanding at a rate that threatens the genetic and phenotypic integrity of the ancient-origin red deer in Co. Kerry. This study builds on the preliminary work of McDevitt et al. (2009) by genotyping a large sample of individuals at a set of 22 microsatellites which are highly diagnostic for red deer and Japanese sika and moderately diagnostic for red deer and wapiti and a single mtDNA marker that is diagnostic for red deer, Japanese sika and Manchurian sika. The specific objectives were:

1. To assess the current extent of hybridisation and introgression between Cervus deer in Ireland and whether they threaten the purity of either parental taxon.

2. To determine, if possible, the initial direction of hybridisation. 
3. To investigate whether any red deer-Japanese sika hybrids outside Co. Wicklow derive from the Wicklow hybrids or from independent hybridisation events.

4. To investigate the accuracy with which hybrids are identified from hunter-assigned phenotype.

5. To suggest management actions to protect putatively pure populations from hybridisation.

\section{Materials and methods}

\section{Sampling}

Samples were obtained from seven counties in the Republic of Ireland and a single county in Northern Ireland covering the major red deer and Japanese sika populations (Carden et al. 2011). In total 392 individuals were collected for genotyping (details of the final dataset in Table 1; see Fig. 1 for overview of sampling). Most samples obtained from Co. Kerry, Co. Cork and Co. Wicklow were shot during the 2011-2012 season; the remaining samples, collected from all eight counties, were sampled between 2006 and 2012. 51 samples, drawn from five counties, were in common with McDevitt et al. (2009) (Table 1). Samples consisted of ear tips collected into $99 \%$ ethanol.

\section{DNA analysis}

Genomic DNA was extracted from samples with the DNeasy Blood and Tissue Kit (Qiagen) according to the manufacturer's instructions. Individuals were genotyped at a panel of 22 diagnostic microsatellite markers following previously published protocols (Senn and Pemberton 2009; Supplementary Table S1). Originally derived from cattle (Bos taurus) and sheep (Ovis aries), these markers were selected to discriminate between red deer and Japanese sika because when used to genotype 44 red deer and 44 sika from diverse geographical locations, they shared no common alleles (Slate 1998; Goodman et al. 1999). In addition, they have some discriminatory power between red deer and wapiti (10/22 strongly diagnostic loci). The characteristics of the marker panel in Manchurian sika or sambar are unknown. PCR products were run on an ABI3730 capillary sequencer (Applied Biosystems), using the internal standard Genescan LIZ 500 (Applied Biosystems). Fragment analysis was carried out using Genemapper version 4.0 (Applied Biosystems).

Individuals were also screened for their haplotype in the mitochondrial control region, which in deer includes a diagnostic number of 39 bp tandem repeats: red deer have a single repeat, Japanese sika have three and Manchurian sika have seven (Cook et al. 1999). Amplification followed a published protocol (Cook et al. 1999) and repeat number was determined by assay on $4 \%$ agarose gels stained with ethidium bromide (Goodman et al. 1999) when red deer have a $\sim 350$ bp band, Japanese sika a $\sim 430$ bp band and Manchurian sika a $\sim 590$ bp band.

Data analysis

The Bayesian clustering software Structure 2.3.3 (Pritchard et al. 2000; Falush et al. 2003, 2007) was used to analyse the extent of individual and population admixture using the microsatellite genotype data in a number of separate datasets. In the first analysis (analysis 1) the dataset of all Irish deer was supplemented with genotypes for 50 putatively pure red deer from central Scotland, 50 putatively pure Japanese sika from Kintyre, Scotland and 49 Canadian wapiti as control samples (total $n=523$ ). For analysis 2 the wapiti samples and any Irish deer showing signs of wapiti introgression were deleted from the analysis 1 data set (total $n=471$ ). The number of inferred, genetically distinct populations $(\mathrm{K})$ that maximises the likelihood ( $\mathrm{Ln}$ $\operatorname{Pr}(\mathrm{X} \mid \mathrm{K}))$ of the dataset, assuming they are in HardyWeinberg equilibrium and linkage equilibrium, was estimated by running five independent replicates at different values of $\mathrm{K}$ (1-8) and selecting the smallest value of $\mathrm{K}$ with the highest log likelihood $(\operatorname{Ln} \operatorname{Pr}(\mathrm{X} \mid \mathrm{K}))$, prior to it plateauing (Pritchard et al. 2000). A more objective approach for estimating the best value of $\mathrm{K}$, estimating the maximum rate of change in the log probability of the data between consecutive values of $K(\Delta K)$, was also used to indicate the appropriate value of K (Evanno et al. 2005). Analyses 1 and 2 were run with the same parameters as in previous studies (Senn and Pemberton 2009), namely the standard model of admixed ancestry (with the parameter $\alpha$ inferred from the data, using a uniform prior) and the model of correlated allele frequency $(\lambda=1)$, a burnin of $5 \times 10^{4}$ and a run length of $10^{6}$ Markov chain Monte Carlo steps. This is well within the suggested parameter values of Pritchard et al. (2000) and parameters appeared to converge correctly. Null alleles can cause deviation from HardyWeinberg equilibrium by causing a systematic pattern of missing genotype data and can jeopardise rates of hybridisation observed (Falush et al. 2003; Senn 2009). The frequency of null alleles was therefore estimated concurrently by incorporating a row of "999" values into the second line of the data set and activating the option Recessive Alleles $=1$. This function enables Structure to 'suspect' particular alleles as null alleles if, for example, they exhibit allele-specific PCR failure. It will then treat these suspected null alleles as recessive instead of missing data and estimate their frequency at each locus (Falush et al. 2007; Senn 2009). Structure output data were 
Table 1 Sample sizes, hunter-assigned phenotypes and genetic data set completeness for the 374 individuals successfully genotyped (at least 20 out of the 22 nuclear markers genotyped), shown for the eight counties sampled

\begin{tabular}{|c|c|c|c|c|c|c|c|}
\hline County & $\begin{array}{l}\text { Total number of } \\
\text { individuals (no. of } \\
\text { individuals in common } \\
\text { with McDevitt et al. 2009) }\end{array}$ & $\begin{array}{l}\text { No. of } \\
\text { phenotypic } \\
\text { red deer }\end{array}$ & $\begin{array}{l}\text { No. of } \\
\text { phenotypic } \\
\text { sika }\end{array}$ & $\begin{array}{l}\text { No. of } \\
\text { phenotypic } \\
\text { hybrid animals }\end{array}$ & $\begin{array}{l}\text { No. animals } \\
\text { not assigned } \\
\text { phenotype }\end{array}$ & $\begin{array}{l}\text { Nuclear } \\
\text { dataset } \\
(\% \text { complete })\end{array}$ & $\begin{array}{l}\text { mtDNA } \\
\text { dataset } \\
(\% \text { complete })\end{array}$ \\
\hline Donegal & 13 & 12 & 0 & 1 & 0 & 95.45 & 100 \\
\hline Tyrone & $2(1)$ & 0 & $2(1)$ & 0 & 0 & 100.00 & 100 \\
\hline Sligo & 4 & 4 & 0 & 0 & 0 & 95.45 & 100 \\
\hline Mayo & $16(3)$ & $15(3)$ & 1 & 0 & 0 & 95.45 & 100 \\
\hline Galway & $12(5)$ & $12(5)$ & 0 & 0 & 0 & 96.59 & 100 \\
\hline Kerry & $114(21)$ & $37(21)$ & 74 & 0 & 3 & 98.88 & 100 \\
\hline Cork & 15 & 0 & 10 & 4 & 1 & 99.70 & 100 \\
\hline Wicklow & $198(21)$ & $13(6)$ & $123(14)$ & 49 (1) & 13 & 98.90 & 100 \\
\hline
\end{tabular}

Values given in parentheses indicate animals analysed in a previous study by McDevitt et al. (2009)

(a)

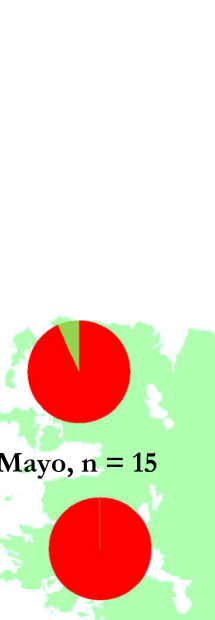

Galway, $\mathrm{n}=12$

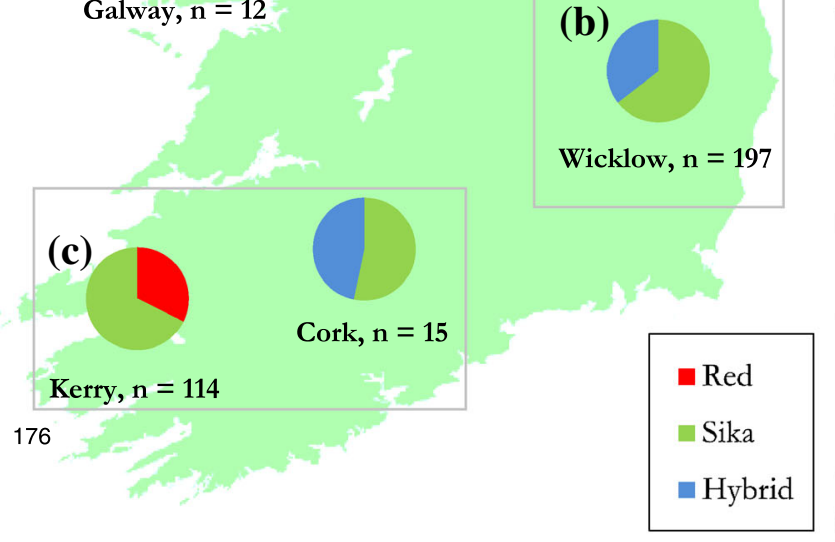

Fig. 1 a Overview of the proportion of pure red deer, pure sika and hybrids based on their nuclear genotype (see Methods and Results) around Ireland and in further detail from b Co. Wicklow, where 1 Glen of Imaal, 2 Ballinagee, 3 Oakwood, 4 Kippure, 5 Luggala, 6 Ballyknockan, 7 Carrigeenduff Upper, 8 Carrigeenduff Lower, 9 Turlough Hill, 10 Brockagh, 11 Derrybawn, 12 Camaderry, 13 Lugduff, 14 Ballinacor, 15 Carawaystick, 16 Ballyward,
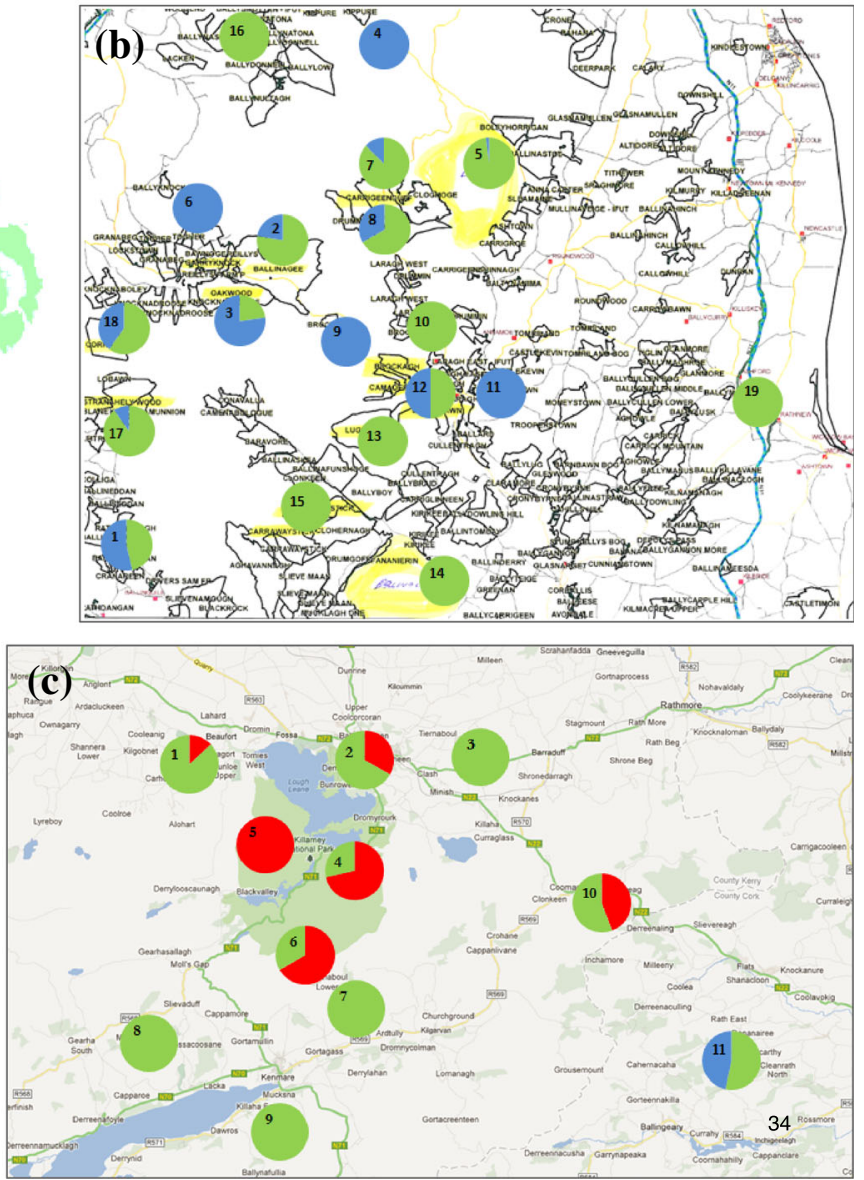

17 Stranahely, 18 Corragh, 19 Ashford (background markings in yellow irrelevant) and from c Co. Kerry and Co. Cork, where 1 West Lough Leane, 2 East Lough Leane, 3 North East region of Killarney National Park, 4 South Muckross Lake, 5 Kingsboro Upper Lake, 6 Southern border of the Killarney National Park, 7 Inside the R560 road, 8 East Kenmare, 9 South Kenmare, 10 South East Kerry, 11 Cork 
manipulated using the software Distruct (Rosenberg et al. 2002) for illustrative purposes.

Analysis by Structure 2.3.3 generated a $Q$ value for each individual, which represents the estimated proportion of ancestry to each of $\mathrm{K}$ groups. When simulations are run at $\mathrm{K}=2$ (as is typical for hybridisation between two taxa), the $\mathrm{Q}$ values for membership to one of the two ancestral populations can be used as an index of the hybrid status of an individual; here $\mathrm{Q}=0$ represents a sika and $\mathrm{Q}=1$, a red deer. Delimiting the proportion of admixture that qualifies as a hybrid is difficult, principally due to the possibility that at some loci there may be ancestral allele sharing in the taxa under consideration. Here a hybrid was defined on the basis of nuclear markers as an individual returning a $\mathrm{Q}$ value of $0.05 \leq \mathrm{Q} \leq 0.95$ between two taxa, following previous practice (Senn and Pemberton 2009). Such an animal was identified as a 'nuclear hybrid' based on the microsatellite markers. Individuals outside these boundaries were defined as 'pure', although may still contain introgressed alleles beyond the detection limit of the markers.

When mitochondrial DNA analysis and Structure analysis were combined, some further hybrids were identified when the mtDNA haplotype was discordant with a 'pure' nuclear genotype (i.e. red deer mtDNA in animals with $\mathrm{Q}<0.05$ or sika mtDNA in animals with $\mathrm{Q}>0.95$ ). This latter type of hybrid, was defined as a 'mitochondrial hybrid' and indicates introgression beyond the resolution of the nuclear markers.

The direction of initial hybridisation events (i.e. which taxon was the female parent) can only be assessed from cytonuclear data in F1 hybrids. An F1 individual should have a $Q$ close to 0.5 in a $K=2$ Structure analyses and it should be heterozygous for red deer and sika alleles at all loci. In order to determine whether we had sampled any F1 hybrids we examined the posterior allele frequencies for the parental taxa generated by Structure following analysis 2 and assigned alleles as red deer-specific, sika-specific or inconclusive, according to conservative criteria (see Supplementary Table S4). The genotypes of hybrids were recorded according to the origin of each allele at each locus to determine the proportion of loci that were red-sika heterozygous relative to all loci genotyped in that individual.

Since this study revealed a previously undocumented hybrid population in Co. Cork, we sought to determine the origin of the sika and red deer contributing to the Co. Cork population and specifically whether they could have been translocated as hybrids from Co. Wicklow or were descended from an independent hybridisation event. For sika, this was achieved by running analysis 3 , a Structure analysis using all individuals that were defined as pure Japanese sika in analysis 2, i.e. they returned a $Q<0.05$. Structure run parameters were as described above. From this we identified the likely source of the Co. Cork sika. Because no apparently pure red deer $(\mathrm{Q}>0.95$ in analysis 2) were sampled in Co. Cork, the origin of the red deer alleles in the Co. Cork population cannot be determined in the same way. Instead, using the posterior allele frequencies from analysis 2 (see Supplementary Table S4), we identified the red deer alleles found among Co. Cork hybrids and asked whether or not they occurred in other Irish deer populations, for example Co. Kerry or Co. Wicklow.

To address the accuracy with which hunters identified hybrids between red deer and Japanese sika, the Q value derived from analysis 2 and mitochondrial haplotype for animals from Co. Wicklow and Co. Cork was compared with the phenotype assigned by the hunter when the deer was sampled.

\section{Results}

\section{Genetic diversity}

Across the 392 individuals sampled, genotypes were obtained for at least 20 of the 22 nuclear markers for 374 individuals and the mitochondrial haplotype was determined for all individuals (Table 1). Genetic diversity indices were calculated for all microsatellite loci within phenotypic red deer and phenotypic sika (Supplementary Table S2). Mean allelic diversity was higher in red deer (7.6), than in sika (5.7). Results should be interpreted with caution given that, as described below, several individuals of both phenotypes were hybrids.

\section{Hybridisation}

Analysis 1: All red deer, sika and wapiti genotypes $(n=523)$

The log likelihoods calculated in Structure revealed $\mathrm{K}=2$ as the smallest number of genetic clusters that was optimal to describe the population structure, with an average $\operatorname{Ln} \operatorname{Pr}$ (XIK) (natural logarithm of the probability of data X, conditional on K) of $-23,028.94$ (s.d. 5.57) and a rate of change of 2,124.27 (Supplementary Figure S1). At this value of $\mathrm{K}$, as might be predicted from the choice of markers, red deer and Japanese sika were differentiated, but not wapiti, which clustered with red deer (see Supplementary Figure S2). The next most likely structure was $\mathrm{K}=3$ with a likelihood of $-21,009.2$ (s.d. 795.49) and a rate of change of 2.54 and at this $\mathrm{K}$ wapiti were differentiated from red deer and Japanese sika (Supplementary Figure S3). Allele frequencies for the three taxa generated at $\mathrm{K}=3$ are shown in Supplementary Table S3. 
There is little evidence for introgression of Irish deer populations by wapiti (Supplementary Figures S3 and S4). Using the criterion of $\mathrm{Q}>0.05$ membership to wapiti, in total we found one red-like individual with low-level wapiti introgression from Co. Mayo (0.873/0.002/0.125 membership to red/sika/wapiti respectively) and one redlike individual with low-level sika and wapiti introgression from Co. Wicklow (0.831/0.111/0.057 membership to red/ sika/wapiti respectively). Given that 374 Irish deer were studied, this suggests a very low rate of introgressed individuals $(0.53 \%)$, each with a very low proportion of wapiti alleles. A single individual amongst the red deer control animals from central Scotland (RAL09) also showed wapiti introgression. In all three cases the $90 \%$ credible intervals of membership to wapiti spanned zero, so the inference of introgression is very tentative.

On the other hand this analysis revealed a spectrum of red-sika hybrids in Co. Wicklow and Co. Cork (Supplementary Figures S3 and S4). Since it is possible that the inclusion of wapiti genotypes could confound the analysis of red-sika hybridisation, in analysis 2 we repeated the analysis after removing the 49 wapiti control samples, the control Scottish red deer with wapiti introgression and the two Irish deer with evidence of wapiti introgression.

\section{Analysis 2: All red deer and sika $(n=471)$}

As might be expected from analysis 1 , the log likelihoods calculated in Structure showed $\mathrm{K}=2$ was the smallest number of genetic clusters that was optimal to describe the population structure, with an average $\operatorname{Ln} \operatorname{Pr}(\mathrm{XIK})$ of $-18,585.8$ (s.d. 3.25) and a rate of change of 3,220.86 (Fig. 2). Allele frequencies for the population clusters at $\mathrm{K}=2$ are shown in Supplementary Table S4. Analysis 2 supports the results of analysis 1 in showing that a substantial proportion of deer sampled in Co. Wicklow and Co. Cork are introgressed hybrids (with individual Q estimates very similar to those estimated in analysis 1) while remaining individuals sampled in these counties were 'pure' sika (Fig. 1; Table 2 and Supplementary Figure S5). In contrast, no individuals sampled from the North West or Co. Kerry were identified as hybrids. Across all Irish samples, a total of 215 'pure' sika, 80 'pure' red deer and 77 hybrids were sampled based on their nuclear genotype. Of the hybrids, $91 \%$ were from Co. Wicklow and $9 \%$ from Co. Cork. Below, we describe results from each of the main sampling areas in more detail.

Across the five counties sampled in the North and West, genetic analysis indicated that we sampled 43 'pure' red deer and three 'pure' sika (Fig. 1a; Table 2, Supplementary Figure S5). These putatively pure red deer were sampled from Co. Donegal $(n=13)$, Co. Sligo $(n=4)$, Co. Mayo
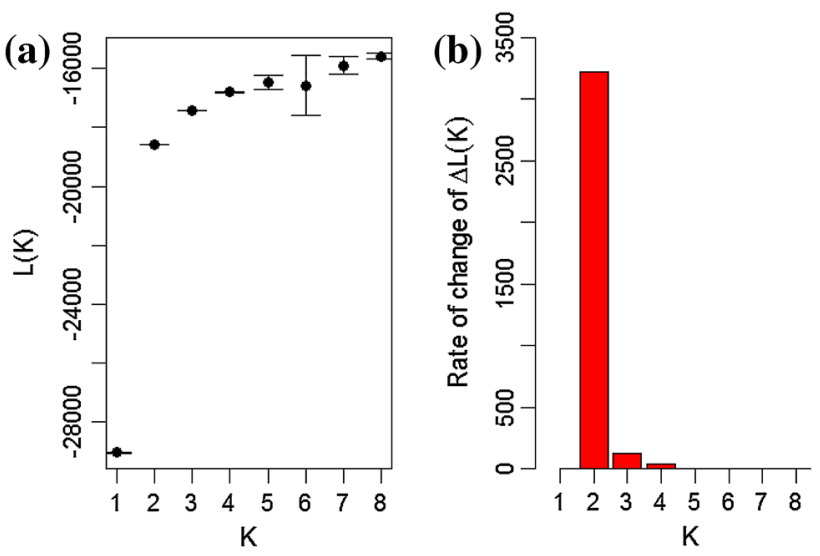

Fig. 2 Assessment of the most likely number of populations in analysis 2 using Structure 2.3.3. a shows the log likelihood (with standard deviation from five runs) of the value of $\mathrm{K}$ (number of populations) given the dataset and $\mathbf{b}$ gives the rate of change in log likelihood between values of $K$. Both provide evidence that $K=2$ are the most likely

$(n=14)$ and Co. Galway $(n=12)$ and putatively pure sika were sampled from Co. Tyrone $(n=2)$ and Co. Mayo $(n=1)$. Since we found no red-sika hybrids, there is no genetic evidence of hybridisation in this region; however, since sample sizes per site were generally very low, this is a tentative inference.

In Co. Wicklow, we sampled 127 'pure' sika individuals from 16 out of the 20 sites and 70 hybrid individuals from 13 of the sites, (Fig. 1b; Table 2; Supplementary Figures S5). No 'pure' red deer were sampled from this region. Whilst hybridisation appears to be extensive at particular sites within Co. Wicklow (e.g. $100 \%$ hybrids sampled from Kippure, Ballyknockan, Turlough Hill, Derrybawn), nuclear hybrids are almost absent from others (e.g. Luggala; Fig. 1b). Among the hybrids, there were over twice as many genetically red-like individuals $(0.5<\mathrm{Q} \leq 0.95 ; n=51)$ compared to sika-like individuals $(0.05 \leq \mathrm{Q}<0.5 ; n=19)$.

In Co. Kerry, genetic analysis indicates that we sampled 77 'pure' sika individuals and 37 'pure' red deer individuals (Fig. 1c; Table 2; Supplementary Figure S5). The putatively pure sika animals were sampled from nine of the ten sample sites (all except Kingsboro, from which only two samples were obtained), while the putatively pure red deer were sampled from six sites.

However, in neighbouring Co. Cork, seven of the 15 individuals sampled were hybrid based on genetic analysis, while the remainder were putatively pure sika (Fig. 1c; Table 2; Supplementary Figure S5). The seven hybrids had $90 \%$ credible intervals which did not span zero or one, indicative of genuine hybrid status. 
Table 2 Admixture classification of all individuals in analysis 2, based on Q values from Structure 2.3 .3 with $\mathrm{K}=2$ and following the classification approach of Senn and Pemberton (2009)

\begin{tabular}{|c|c|c|c|c|c|c|c|c|c|c|}
\hline \multirow[t]{2}{*}{ Category } & \multirow[t]{2}{*}{ Q } & \multicolumn{8}{|l|}{ County } & \multirow{2}{*}{$\begin{array}{l}\text { Total } \\
\text { No. }(\%) \\
\text { all sites }\end{array}$} \\
\hline & & $\begin{array}{l}\text { No. }(\%) \\
\text { Co. } \\
\text { Donegal }\end{array}$ & $\begin{array}{l}\text { No. }(\%) \\
\text { Co. } \\
\text { Tyrone }\end{array}$ & $\begin{array}{l}\text { No. }(\%) \\
\text { Co. } \\
\text { Sligo }\end{array}$ & $\begin{array}{l}\text { No. }(\%) \\
\text { Co. } \\
\text { Mayo }\end{array}$ & $\begin{array}{l}\text { No. }(\%) \\
\text { Co. } \\
\text { Galway }\end{array}$ & $\begin{array}{l}\text { No. }(\%) \\
\text { Co. } \\
\text { Kerry }\end{array}$ & $\begin{array}{l}\text { No. }(\%) \\
\text { Co. } \\
\text { Cork }\end{array}$ & $\begin{array}{l}\text { No. }(\%) \\
\text { Co. } \\
\text { Wicklow }\end{array}$ & \\
\hline $\begin{array}{l}\text { 'Pure' red deer } \\
\text { ancestry }\end{array}$ & $0.95<\mathrm{Q} \leq 1$ & $13(100)$ & $0(0)$ & $4(100)$ & $14(93.3)$ & $12(100)$ & $37(32.5)$ & $0(0)$ & $0(0)$ & $80(21.5)$ \\
\hline $\begin{array}{l}\text { Red-like hybrid } \\
\text { with recent } \\
\text { sika ancestry }\end{array}$ & $0.50<\mathrm{Q} \leq 0.95$ & $0(0)$ & $0(0)$ & $0(0)$ & $0(0)$ & $0(0)$ & $0(0)$ & $0(0)$ & $51(25.9)$ & $51(13.7)$ \\
\hline $\begin{array}{l}\text { Sika-like hybrid } \\
\text { with recent red } \\
\text { deer ancestry }\end{array}$ & $0.05 \leq \mathrm{Q}<0.50$ & $0(0)$ & $0(0)$ & $0(0)$ & $0(0)$ & $0(0)$ & $0(0)$ & 7 (46.6) & $19(9.6)$ & $26(7)$ \\
\hline $\begin{array}{c}\text { 'Pure' sika } \\
\text { ancestry }\end{array}$ & $0 \leq \mathrm{Q}<0.05$ & $0(0)$ & $2(100)$ & $0(0)$ & $1(6.7)$ & $0(0)$ & $77(67.5)$ & $8(53.3)$ & $127(64.5)$ & $215(57.8)$ \\
\hline
\end{tabular}

A red-like hybrid with recent sika ancestry was defined as an individual returning a $\mathrm{Q}$ value of $0.50<\mathrm{Q} \leq 0.95$ whilst a sika-like hybrid with recent red-like ancestry was defined as $0.05 \leq \mathrm{Q}<0.5$. Credible regions were not used in these designations

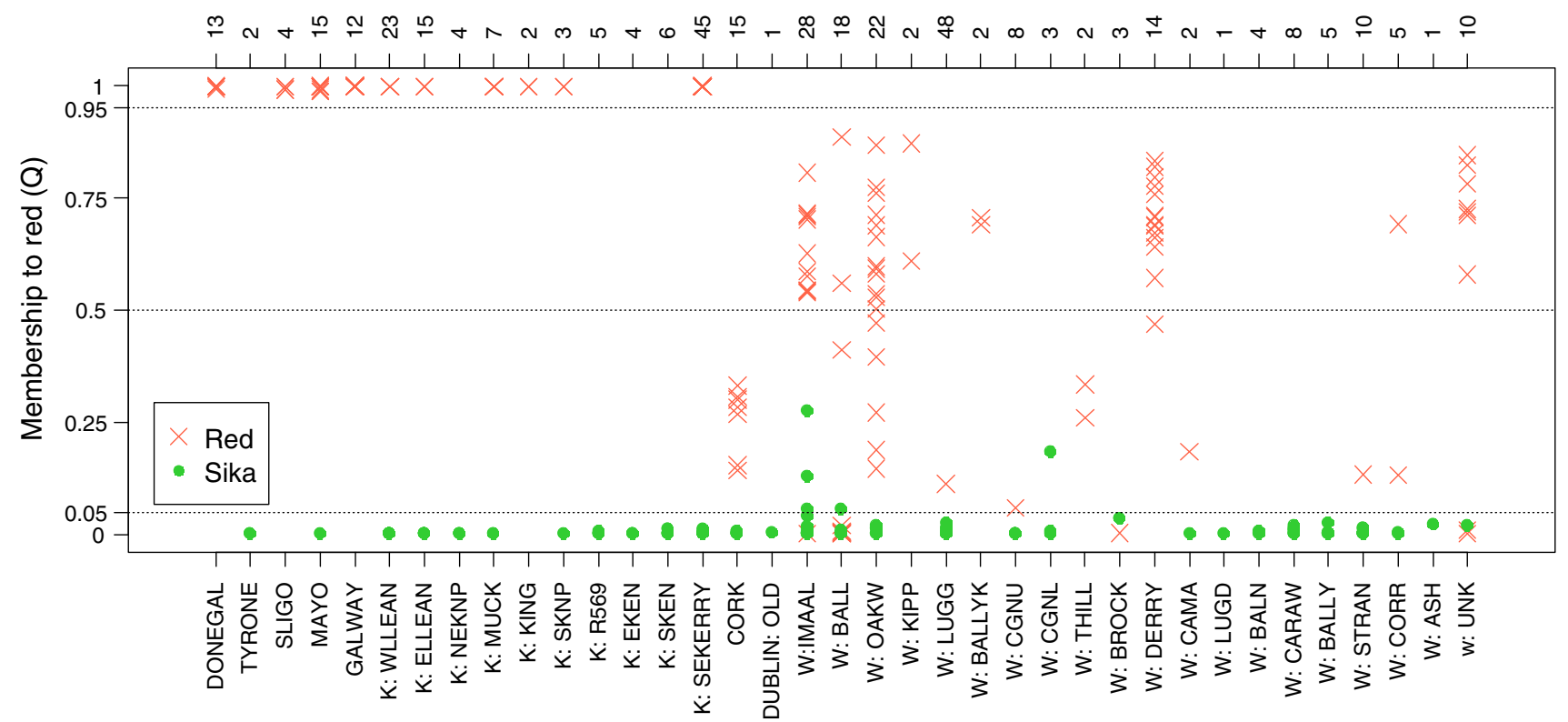

Fig. 3 The membership to red deer (Q), as calculated by Structure 2.3.3 plotted against the site from which the individual was obtained. The mtDNA species haplotype the individual carried is indicated by a cross or dot. Abbreviated population codes are as follows: "K:" relates to Co. Kerry sites for which WLLEAN West Lough Leane, ELLEAN East Lough Leane, NEKNP North East region of Killarney National Park, MUCK South Muckross Lake, KING Kingsboro Upper Lake, SKNP Southern border of the Killarney National Park, R569 Inside the R560 road, EKEN East Kenmare, SKEN South Kenmare, SEKERRY South East Kerry, CORK Co. Cork,

\section{Mitochondrial DNA}

Mitochondrial DNA analysis added further resolution to the Structure analyses. First, it is important to note that the mitochondrial marker is not diagnostic for wapiti and no Manchurian sika haplotypes were detected. No red deer- then " $W$ " refers to Co. Wicklow sites for which IMMAL Glen of Imaal, BALL Ballinagee, OAKW Oakwood, KIPP Kippure, $L U G G$ Luggala, BALLYK Ballyknockan, $C G N U$ Carrigeenduff Upper, $C G N L$ Carrigeenduff Lower, THILL Turlough Hill, BROCK Brockagh, DERRY Derrybawn, CAMA Camaderry, LUD Lugduff, BALN Ballinacor, CARAW Carawaystick, BALLY Ballyward, STRAN Stranahely, CORR Corragh, ASH Ashford and UNK Co. Wicklow, unknown location. Numbers on top indicate number of individuals per sample site

Japanese sika cytonuclear disequilibria were noted in counties of the North West or Co. Kerry. However, among the red-sika hybrids in Co. Wicklow and Co. Cork, the red deer mitochondrial haplotype predominates (Fig. 3). None of the 131 deer with a $\mathrm{Q}>0.5$ (i.e. red-like) carried a Japanese sika mtDNA haplotype but 31/214 (14.5\%) 
individuals with a $\mathrm{Q}<0.5$ (i.e. sika-like) carried a red deer haplotype. Amongst the 31 sika-like individuals with $\mathrm{Q}<0.5$ and a red deer haplotype, ten were animals considered 'pure' sika $(\mathrm{Q}<0.05)$ from their nuclear markers (Fig. 3) and these were all sampled from Co. Wicklow. The inclusion of these mitochondrial hybrids increased the total number of hybrids found, based on either nuclear genotype or mitochondrial haplotype from 77 to 87 or by $13 \%$.

The initial direction of hybridisation

No F1 individuals were detected, since no individuals were even close to $100 \%$ heterozygous for red deer and sika alleles (Supplementary Figure S6).

Genetic origins of Co. Cork hybrids

In Structure analysis 3, comprising only 'pure' Japanese sika samples from Ireland, two genetically distinct populations were identified: Co. Wicklow sika and the small number of sika sampled from the North West clustered separately from the Co. Kerry sika (Supplementary Figure S7). The Co. Cork sika clustered with the Co. Kerry sika, suggesting that they derived from the long-standing Co. Kerry population.

The Co. Cork hybrids had a maximum of two different introgressed red deer alleles per locus, whereas the Co. Wicklow hybrids had a maximum of six different introgressed red deer alleles. Furthermore, at four out of the 22 loci, the Co. Cork hybrids had a single red deer allele which was present in neither Co. Kerry red deer nor in Co. Wicklow hybrids (Supplementary Figure S8). Whilst two of these alleles were found in red deer from the North West counties sampled, the remaining two were absent from all other red deer sampled from Ireland in this project, but have been observed in Scottish red deer (S. Smith, pers. obs).

Accuracy of hunter-assigned phenotype

Amongst all deer assigned a phenotype from Co. Wicklow and Co. Cork, 156 out of 198 (79\%) were identified correctly according to their $\mathrm{Q}$ value based on nuclear genotype and mitochondrial haplotype. Of the $42(21 \%)$ animals that were misidentified, 25 were identified as sika but were actually hybrids (including 9 that were mitochondrial hybrids) and four were identified as hybrids but genotyped as 'pure' sika (Fig. 4). Of the 16 animals phenotyped as sika but that turned out to be nuclear hybrids only three had $\mathrm{Q}$ values $<0.1$ and the most 'red-like' had a $\mathrm{Q}$ value of 0.726 , showing that these animals were relatively intermediate. Of the thirteen animals which were identified as red deer, twelve were actually hybrid and one was a 'pure'

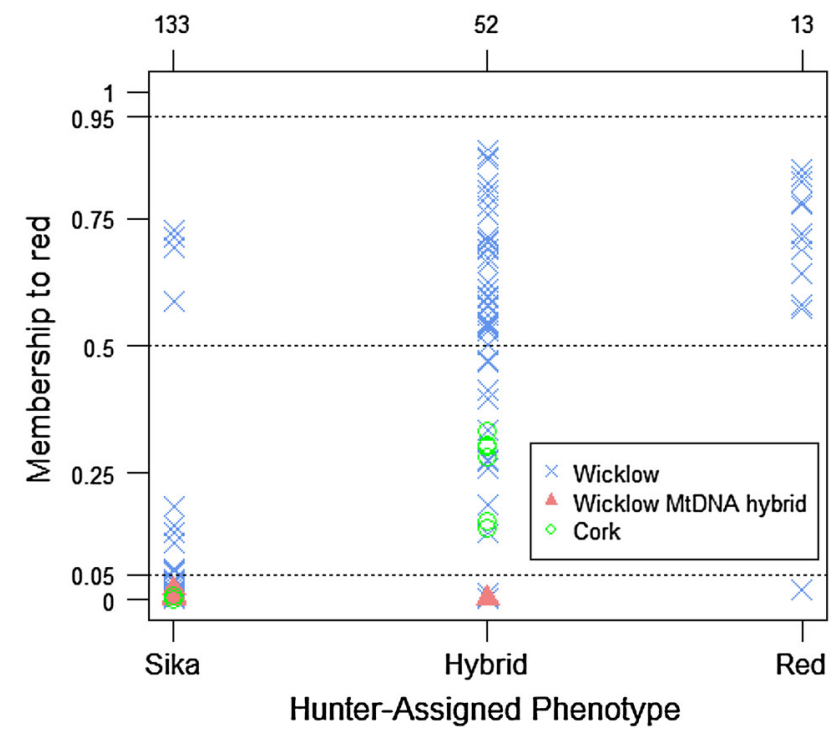

Fig. 4 The estimated proportion of ancestry (Q) for all animals from Co. Wicklow and Co. Cork $(n=198)$ plotted against their hunterassigned phenotype. Mitochondrial hybrids, which are beyond the detection of the nuclear markers, were only found in Wicklow and are represented by triangles. 13 animals from Wicklow were excluded as they did not have a phenotype assigned

sika; with no 'pure' red deer sampled at these sites, all deer identified as such were incorrect.

\section{Discussion}

Although Ireland has no native deer, it has a historically and genetically interesting red deer population worthy of genetic conservation threatened by more recent introductions of members of the genus Cervus. Our genetic survey using a large panel of diagnostic markers provides the most robust evidence to date of the extent of hybridisation amongst species of the genus Cervus in Ireland and has allowed us to investigate the objectives outlined earlier.

Hybridisation and introgression between Irish red deer and the exotic North American wapiti appears to have been negligible. If wapiti introgression was widespread, we would have expected multiple sampled individuals to show wapiti alleles, instead of which we found just two: one in Co. Mayo and one in Co. Wicklow, both of which had Q values with $90 \%$ credible intervals overlapping zero. At this level, it is impossible to distinguish whether the cases are genuine or whether they reflect inadequacy of the marker panel or the control wapiti samples, or ancestral polymorphism between the species. Sample sizes from sites in the North West were small, so ideally further individuals would be sampled there to confirm the situation. However, the observation of negligible wapiti introgression accords with the view of Whitehead (1964) who 
regarded it "extremely unlikely" that wapiti material from the Powerscourt introduction would have persisted long. More strenuous attempts have been made to detect introduced wapiti genetics in Scottish red deer, yet recent surveys there using a (different) microsatellite panel and mitochondrial and Y-chromosome markers also found relatively little genetic impact of wapiti (Pérez-Espona et al. 2009b; 2011; 2013). Similarly, with the only tool available to us, the mtDNA, we found no evidence for Manchurian sika haplotypes in Ireland.

Since the introduction of the Japanese sika in 1860, the genetic consequences for Irish red deer have been very substantial. In this study 80 out of 197 (41\%) of the deer sampled from Co. Wicklow were hybrids based on either their nuclear genotype or mitochondrial haplotype, whilst 7 out of $15(47 \%)$ of those sampled from Co. Cork were also hybrids. On the other hand, there was no evidence for nuclear or mitochondrial introgression from Japanese sika into red deer in samples obtained from the North West or, more remarkably, Co. Kerry. We will now discuss these results for each region.

It has long been established that Co. Wicklow contains a hybrid deer swarm, but its extent has only become clear as more informative genetic analyses have been conducted. In this study no 'pure' red deer were sampled from this location, 80 out of 197 deer sampled $(41 \%)$ were hybrids (including mitochondrial hybrids) and the remaining 117 out of $197(59 \%)$ were 'pure' sika. These results build on those of McDevitt et al. (2009) who studied 43 Co. Wicklow deer with eight microsatellite loci (including three of the loci used in this study) and Structure analysis. Overall, these authors found 2 'pure' red deer (5\%), 12 hybrids (of which one was a mitochondrial hybrid) (28\%) and 29 'pure' sika $(67 \%)$. Although we cannot be sure, since largely different samples were analysed, part of the difference in proportions between studies is probably due to the greater resolution of the marker panel used in this study. The complete lack of pure red deer in our analysis is consistent with the observations of Harrington (Harrington 1979) using rocket immuno-electrophoresis. The existence of the Co. Wicklow mitochondrial hybrids, both in this study and in McDevitt et al. (2009), indicates that introgression of red deer genes into sika has extended beyond the detection of even our current microsatellite marker panel, and that other individuals which typed as 'pure' sika and had sika mtDNA were probably advanced backcrosses to sika. Since 30-40 generations have passed since hybrids were first noted in Powerscourt Park (Powerscourt 1884) and the number of markers required to detect backcrossed individuals increases rapidly with each generation (Boecklen and Howard 1997) a substantially larger maker panel (or whole genome approach, as technology improves) would be required to detect which sika currently assessed as pure are hybrids. It remains to be seen whether Harrington's contention that there are no pure Japanese sika left in Co. Wicklow is also true (Harrington 1979).

There are two strong parallels between the observations made in this study in Co. Wicklow and those of Senn and Pemberton (2009) in Kintyre, Scotland. First, in both areas advanced sika-like backcrosses also often carry red deer mtDNA (Senn and Pemberton 2009) whereas putatively pure red deer with sika mtDNA have not yet been observed. In both regions red deer females were definitely involved either in starting the hybrid swarm or in subsequent matings with hybrid males. Second, the extent of introgression is spatially variable within Co. Wicklow, with detected hybrids concentrated in sites including Kippure, Ballyknockan and Derrybawn whilst Luggala remains largely free of hybrids (Figs. 1b, 3). Luggala is known to operate a selective cull in which odd-looking animals are removed and may be less prone to infiltration of introgressed animals from elsewhere than the other sites studied. While the apparently hybrid-free sites are likely to have some low-level hybrids not detectable by our marker set (above), this local variation is reminiscent of the observations of Senn and Pemberton (2009) in Kintyre where virtually all the hybrids were detected in one sampling area, and suggests that the spread of introgression can be quite slow for long periods.

Our study suggests that there are no pure red deer left in Co. Wicklow and it seems likely hybridisation has played a role in this extinction. It is clear that sika became the most abundant deer species in Powerscourt Park, since Delap (Delap 1936) reported 60-65 red deer living amongst 500-600 sika, the latter of which had 'over-run the entire park'. As the (potentially hybridised) park population escaped and spread out into Co. Wicklow, they would have met a pre-existing red deer population, which is likely to have been small at the time. It is possible that other forces such as feeding competition with sika or sheep, an increased afforestation programme from the 1960s leading to habitat loss and selective hunting of red deer may have contributed to the demise of red deer in the region. It also seems likely that strongly skewed species densities made introgression into the rarer red deer more likely. Other anthropogenically induced introgressions probably result from a similar imbalance, for example dwindling European wolf populations (Canis lupus) increasingly hybridise with (common) domestic dogs (C. familiaris) (Vilà et al. 2003).

Despite a long history of sympatry (since 1864), our survey, like that of McDevitt et al. (2009) found no detectable nuclear or mitochondrial introgression amongst Co. Kerry red deer and sika. Given that hybridisation has been recorded in other circumstances where the two species are sympatric, the lack of hybridisation in Co. Kerry demands explanation. One hypothesis is that the Co. Kerry red deer 
are genetically and phenotypically so divergent from other red deer that hybridisation is less likely. As a result of their Neolithic introduction to Ireland, and perhaps due to bottlenecks since, the Co Kerry red deer are not only genetically divergent from other red deer in the rest of Ireland (Carden et al. 2012) but also low in genetic diversity. Using eight nuclear markers McDevitt et al. (2009) concluded that mtDNA nucleotide and haplotype diversity in Co Kerry was up to ten times lower than in other parts of Ireland. Therefore, their longstanding isolation, restricted genetic diversity and the process of genetic drift may have caused the Co. Kerry red deer to diverge from other red deer populations to the extent that they have become less genetically and phenotypically compatible with the sika they are now in sympatry with, compared to those that originally resided in Co. Wicklow. This process may also be paralleled in the Co. Kerry sika. Only three sika were translocated to Co. Kerry in 1864, very soon after their introduction to Powerscourt Park (and before hybrids were noted in the Park) and they too, being the result of successive bottlenecks, are genetically divergent and depauperate in genetic variation-probably they are purer Japanese sika than any to be found elsewhere in Ireland (Harrington 1979). Furthermore, whether due to genetics or habitat, contemporary Co. Kerry red deer are physically large while contemporary Co Kerry sika are physically small, which probably makes these species less compatible and more likely to mate assortatively than in other areas (Whitehead 1964; McDevitt et al. 2009). Finally, although this would not have been true during the early stages of the introduction, both species are today present in relatively good numbers in Co. Kerry (though red deer are scarcer than sika), meaning each can find its own kind in the mating season.

This is the first time hybrid deer have been reported in Co. Cork, with 7 out of 15 individuals ( $47 \%$ ) being hybrids and the remaining 8 (53\%) being 'pure' sika. A striking feature of the hybrids in this area is that they all carry red deer mtDNA, indicating that one or more female red deer was involved in their ancestry. This population threatens the integrity of the Co. Kerry red deer and sika since at its closest it is only around $20 \mathrm{~km}$ away from the Co. Kerry-Co. Cork border, regarded as "no great distance for a travelling stag" (Whitehead 1964). The dispersal of hybrid animals from Co. Cork into Co. Kerry and successful reproduction with deer there could reduce the prevalent interspecific size dimorphism and disrupt assortative mating.

The origin of the Co. Cork sika and hybrids is undocumented, but we used genetic data to test some hypotheses, in particular whether they had come from Co. Wicklow or were descended from a different hybridisation event. In a Structure analysis based on all 'pure' sika sampled across Ireland, the Co. Cork sika clustered with those from Co. Kerry, which is consistent with a historical record of the establishment of sika from Co. Kerry to sites in and around West Cork (Whitehead 1964). This suggests that, in contrast to our above suggestion, given the correct combination of circumstances, the sika in Co. Kerry are susceptible to hybridisation. The absence of 'pure' red deer in Co. Wicklow or Co. Cork prevented us from conducting a parallel analysis of red deer population structure in order to discover the origin of the red deer contributing to the Co. Cork hybrids. Instead, we examined the red deer alleles present in the hybrids in these two counties and in pure red deer in other Irish populations in order to try and infer the genetic affinity of the red deer population involved in the Co. Cork hybrids. The presence of four private red deer alleles in Co. Cork, at substantial frequencies, suggests an ancestral red deer population independent of either the Co. Wicklow or Co. Kerry populations was involved in the hybridisation events leading to the Co. Cork hybrids. Two of the private alleles occur in red deer sampled in the North West of Ireland, but the other two were not observed in Ireland in this survey, but have been observed in Scottish red deer (S. Smith pers. obs.), so seem likely to be of recent origin in Ireland. Escapees from red deer farms in the area are considered a likely source of the red deer involved in the Co. Cork hybrids (T. Burkitt, pers. obs.). Further investigation into these farms and comparison with European populations may shed light on the exact source of the red deer involved.

In the North West of Ireland, conclusions regarding the extent of red-sika hybridisation are tentative due to small sample sizes. Red deer resident here have a long history of intra-red admixture through various translocations and sika populations still reside in these counties (Whitehead 1964; Carden et al. 2011). Whilst all our samples from counties Donegal, Tyrone, Sligo, Mayo and Galway typed as 'pure' sika and 'pure' red deer, these counties should continue to be monitored for hybridisation.

Our data yield no definitive conclusion about the direction of initial hybridisation events. No F1 individuals were detected in our dataset in that they fulfilled the criteria of $\mathrm{Q} \approx 0.5$ and a genotype heterozygous for red deer and sika alleles at all loci (Supplementary Figure S6). The absence of F1 hybrid animals amongst the samples from Co. Wicklow is unsurprising given the absence of pure red deer in this area, the prolonged period over which hybridisation and introgression are known to have taken place and the advanced state of introgression in the population exemplified by the mitochondrial hybrids (above). In Co. Cork, our small sample $(n=15)$ included neither pure red deer nor F1 hybrids. Despite the absence of F1s in these data, we can comment on an overall bias in these data: in both Co. Wicklow and Co. Cork there are sika-like hybrids with red deer mtDNA, whereas there are no red-like hybrids with sika mtDNA. This points to an appreciable 
role for red deer females and sika males in hybridisation, either in the initial event or in subsequent backcrossing.

Our study has identified a substantial genetic management problem in that there is a hybrid swarm near to large populations of pure sika and red deer in Co. Kerry, of which the red deer have conservation status within Ireland, for genetic reasons. Selective culling is a potential method for managing hybrids, but our analyses suggest it would not be $100 \%$ effective since in Co. Wicklow and Co. Cork combined, hunters misidentified the genetic status of $21 \%$ of deer based on phenotype. In Co. Wicklow, all possible misclassifications occurred except that no deer identified to be pure sika or hybrid were genetically pure red. Examination of Fig. 4 shows that if hunters removed only deer identified as hybrids, they would still leave behind a population containing putative red deer which were all hybrids, quite a few sika which were also hybrids as well as many 'pure' sika. In Co. Cork some hybrids were correctly identified but others were classified as sika. It is also worth remembering that the hunter-assigned phenotypes used here were reported after the animal had been shot and examined; identification under field conditions before the shot is taken is probably even less accurate. Finally, as discussed above, advanced backcross individuals are not detected by our marker panel.

The Co. Kerry red deer population is of high conservation value, within an Irish context, and hitherto no hybridisation with Japanese sika appears to have taken place (McDevitt et al. 2009; this study). However, the hybrids detected in Co. Cork pose a serious threat to both the red deer and the sika in Co. Kerry since they are nearby and presumably less likely to mate assortatively in the presence of red deer or sika. A management plan to selectively shoot hybrids in Co. Cork is unlikely to be totally effective as they cannot all be detected from phenotype (above). An alternative approach, therefore, may be to try and eliminate the deer population in Co. Cork entirely, in order to remove the threat they pose to the Co. Kerry red deer. However, both these options would involve a large investment of resources and labour. They also both carry the risk that heavy culling in an area may displace survivors further afield, with the result that Co. Cork deer might disperse faster toward Co. Kerry than otherwise. A third option might be to try to maintain the situation by culling between the two areas to maintain a deer-free zone, perhaps with the possibility of gradually extending into the Co. Cork area containing hybrids and gradually eliminating deer from the area. Another alternative might be to initiate an immunocontraception programme to limit deer reproduction in the region, perhaps in conjunction with a specific deer management strategy.

The situation in Co. Wicklow is advanced and, whilst there is no evidence that any putatively pure red deer remain, management could be directed toward conspicuous hybrids in the county in attempts to preserve and maximise the purity of the remaining potentially pure Japanese sika at sites in the South, such as Lugduff, Ballinacor, Carawaystick and Luggala. Elsewhere, managers in the North West counties should remain vigilant as the current situation comprising relatively rare sika amongst the large populations of red deer is potentially conducive to hybridisation (Ratcliffe 1987).

Not only management of deer populations, but management of the land could help to reduce hybridisation and introgression. Different landscape features are associated with varying gene flow in Scottish red deer (Pérez-Espona et al. 2008), and similarly, hybridisation patterns may be influenced by patterns of increasing forestry cover in Ireland. Sika appear to prefer forest habitats, such as commercial conifer forestry, and their expansion can parallel that of its planting (Pérez-Espona et al. 2009a). Collaborating with foresters and other landowners could allow deer management to play a role in shaping the layout of future forests in a way that reduces access and suitable corridors for dispersal of the invasive sika and with the leverage that this may also address the potentially economically significant damage that sika may have on Irish forestry.

Acknowledgments We would like to thank all the hunters who provided samples from deer, Helen Senn for developing the marker system and for some genotypes incorporated into this study and Phil Ellis for help with mtDNA haplotyping. Also thanks to Allan McDevitt for useful discussion on certain aspects of this work and contribution of samples. This work was supported by a UK Natural Environment Research Council PhD studentship to SLS.

Open Access This article is distributed under the terms of the Creative Commons Attribution License which permits any use, distribution, and reproduction in any medium, provided the original author(s) and the source are credited.

\section{References}

Allendorf FW, Leary RF, Spruell P, Wenburg JK (2001) The problems with hybrids: setting conservation guidelines. Trends Ecol Evol 16(11):613-622

Boecklen WJ, Howard DJ (1997) Genetic analysis of hybrid zones: numbers of markers and power of resolution. Ecology 78(8):2611-2616

Carden RF, Carlin CM, Marnell F, McElholm D, Hetherington J, Gammell MP (2011) Distribution and range expansion of deer in Ireland. Mamm Rev 41(4):313-325. doi:10.1111/j.1365-2907. 2010.00170.x

Carden RF, McDevitt AD, Zachos FE, Woodman PC, O’Toole P, Rose H, Monaghan NT, Campana MG, Bradley DG, Edwards CJ (2012) Phylogeographic, ancient DNA, fossil and morphometric analyses reveal ancient and modern introductions of a large mammal: the complex case of red deer (Cervus elaphus) in Ireland. Quat Sci Rev 42:74-84. doi:10.1016/j.quascirev.2012. 02.012 
Cook CE, Wang Y, Sensabaugh G (1999) A mitochondrial control region and cytochrome $\mathrm{b}$ phylogeny of sika deer (Cervus nippon) and report of tandem repeats in the control region. Mol Phylogenet Evol 12(1):47-56

Delap P (1936) Deer in Wicklow. Ir Nat J VI:82-89

Di Stefano G, Petronio C (2002) Systematics and evolution of the Eurasian Plio-Pleistocene tribe Cervini (Artiodactyla, Mammalia). Geol Romana 36:311-334

Evanno G, Regnaut S, Goudet J (2005) Detecting the number of clusters of individuals using the software Structure: a simulation study. Mol Ecol 14(8):2611-2620. doi:10.1111/j.1365-294X.2005.02553.x

Falush D, Stephens M, Pritchard JK (2003) Inference of population structure using multilocus genotype data: linked loci and correlated allele frequencies. Genetics 164(4):1567-1587

Falush D, Stephens M, Pritchard JK (2007) Inference of population structure using multilocus genotype data: dominant markers and null alleles. Mol Ecol Notes 7(4):574-578. doi:10.1111/j.14718286.2007.01758.x

Gligor M, Ganzhorn JU, Rakotondravony D, Ramilijaona OR, Razafimahatratra E, Zischler H, Hapke A (2009) Hybridization between mouse lemurs in an ecological transition zone in southern Madagascar. Mol Ecol 18(3):520-533. doi:10.1111/j. 1365-294X.2008.04040.x

Goodman SJ, Barton NH, Swanson G, Abernethy K, Pemberton JM (1999) Introgression through rare hybridization: a genetic study of a hybrid zone between red and sika deer (genus Cervus) in Argyll, Scotland. Genetics 152(1):355-371

Gray AP (1971) Mammalian hybrids. A check-list with bibliography. Commonwealth Agricultural Bureaux, Edinburgh, p 155

Harrington R (1973) Hybridisation among deer and its implications for conservation. Ir For 30(2):64-78

Harrington R (1979) Some aspects of the biology and taxonomy of the deer of the County Wicklow region. Unpublished $\mathrm{PhD}$ thesis, National University of Ireland, University College Dublin, Ireland

Huang L, Chi JX, Nie WH, Wang JH, Yang FT (2006) Phylogenomics of several deer species revealed by comparative chromosome painting with Chinese muntjac paints. Genetica 127(1-3):25-33. doi:10.1007/s10709-005-2449-5

Kidd AG, Bowman J, Lesbarreres D, Schulte-Hostedde AI (2009) Hybridization between escaped domestic and wild American mink (Neovison vison). Mol Ecol 18(6):1175-1186. doi:10.1111/ j.1365-294X.2009.04100.x

Kuwayama R, Ozawa T (2000) Phylogenetic relationships among European red deer, wapiti, and sika deer inferred from mitochondrial DNA sequences. Mol Phylogenet Evol 15(1):115-123

Lancaster ML, Gemmell NJ, Negro S, Goldsworthy S, Sunnucks P (2006) Menage a trois on Macquarie Island: hybridization among three species of fur seal (Arctocephalus spp.) following historical population extinction. Mol Ecol 15(12):3681-3692. doi:10.1111/ j.1365-294X.2006.03041.x

Leary RF, Allendorf FW, Forbes SH (1993) Conservation genetics of bull trout in the columbia and klamath river drainages. Conserv Biol 7(4):856-865. doi:10.1046/j.1523-1739.1993.740856.x

Lowe VPW, Gardiner AS (1975) Hybridisation between red deer (Cervus elaphus) and sika deer (Cervus nippon) with particular reference to stocks in NW England. J Zool 177:553-566

Ludt CJ, Schroeder W, Rottmann O, Kuehn R (2004) Mitochondrial DNA phylogeography of red deer (Cervus elaphus). Mol Phylogenet Evol 31(3):1064-1083. doi:10.1016/j.ympev.2003.10.003

Mallet J (2005) Hybridization as an invasion of the genome. Trends Ecol Evol 20(5):229-237. doi:10.1016/j.tree.2005.02.010

McDevitt AD, Edwards CJ, O'Toole P, O'Sullivan P, O'Reilly C, Carden RF (2009) Genetic structure of, and hybridisation between, red (Cervus elaphus) and sika (Cervus nippon) deer in Ireland. Mamm Biol 74(4):263-273. doi:10.1016/j.mambio. 2009.03.015
Moore GH, Littlejohn RP (1989) Hybridisation of farmed wapiti (Cervus elaphus manitobensis) and red deer (Cervus elaphus). N. Z. J Zool 16(2):191-198

Pérez-Espona S, Pérez-Barbería FJ, McLeod JE, Jiggins CD, Gordon IJ, Pemberton JM (2008) Landscape features affect gene flow of Scottish Highland red deer (Cervus elaphus). Mol Ecol 17(4):981-996. doi:10.1111/j.1365-294X.2007.03629.x

Pérez-Espona S, Pemberton JM, Putman R (2009a) Red and sika deer in the British Isles, current management issues and management policy. Mamm Biol 74(4):247-262. doi:10.1016/j.mambio.2009.01.003

Pérez-Espona S, Pérez-Barbería FJ, Goodall-Copestake WP, Jiggins CD, Gordon IJ, Pemberton JM (2009b) Genetic diversity and population structure of Scottish Highland red deer (Cervus elaphus) populations: a mitochondrial survey. Heredity 102:199-210

Pérez-Espona S, Pérez-Barbería FJ, Pemberton JM (2011) Assessing the impact of past wapiti introductions to Scottish Highland red deer populations using a $\mathrm{Y}$ chromosome marker. Mamm Biol 76(5):640-643. doi:10.1016/j.mambio.2010.10.001

Pérez-Espona S, Hall RJ, Perez-Barberia F, Glass BC, Ward JF, Pemberton JM (2013) The impact of past introductions on an iconic and economically important species, the red deer of Scotland. J Hered 104(1):14-22. doi:10.1093/jhered/ess085

Pitra C, Lutz W (2005) Population genetic structure and the effect of founder events on the genetic variability of introduced sika deer, Cervus nippon, in Germany and Austria (vol 51, pg 95, 2005). Eur J Wildl Res 51(4):295. doi:10.1007/s10344-005-0116-x

Powerscourt V (1884) On the acclimatization of the Japanese deer at Powerscourt. Proceedings of the Zoological Society of London, pp 207-209

Pritchard JK, Stephens M, Donnelly P (2000) Inference of population structure using multilocus genotype data. Genetics 155(2):945-959

Ratcliffe PR (1987) Distribution and current status of sika deer, Cervus nippon, in Great Britain. Mamm Rev 17(1):39-58. doi:10.1111/j.1365-2907.1987.tb00047.x

Rosenberg NA, Pritchard JK, Weber JL, Cann HM, Kidd KK, Zhivotovsky LA, Feldman MW (2002) Genetic structure of human populations. Science 298(5602):2381-2385

Senn HV (2009) Hybridisation between red deer (Cervus elaphus) and Japanese sika (C. nippon) on the Kintyre Peninsula, Scotland. Unpublished $\mathrm{PhD}$ thesis, University of Edinburgh, Edinburgh

Senn HV, Pemberton JM (2009) Variable extent of hybridization between invasive sika (Cervus nippon) and native red deer $(C$. elaphus) in a small geographical area. Mol Ecol 18(5):862-876. doi:10.1111/j.1365-294X.2008.04051.x

Senn HV, Swanson GM, Goodman SJ, Barton NH, Pemberton JM (2010) Phenotypic correlates of hybridisation between red and sika deer (genus Cervus). J Anim Ecol 79(2):414-425. doi:10. 1111/j.1365-2656.2009.01633.x

Shackell GH, Drew KR, Pearse AJT, Amer PR (2003) A cost-benefit analysis of the value of investment in a wapiti hybridisation research programme and the returns to New Zealand venison producers. N. Z. J Agric Res 46(2):133-140

Slate J, Coltman DW, Goodman SJ, MacLean I, Pemberton JM, Williams JL (1998) Bovine microsatellite loci are highly conserved in red deer (Cervus elaphus), sika deer (Cervus nippon) and Soay sheep (Ovis aries). Anim Genet 29:307-315

Vilà C, Walker C, Sundqvist AK, Flagstad O, Andersone Z, Casulli A, Kojola I, Valdmann H, Halverson J, Ellegren H (2003) Combined use of maternal, paternal and bi-parental genetic markers for the identification of wolf-dog hybrids. Heredity 90(1):17-24. doi:10.1038/sj.hdy.6800175

Whitehead GK (1960) The deer stalking grounds of Great Britain and Ireland. Hollis and Carter, London

Whitehead GK (1964) The deer of Great Britain and Ireland. Routledge and Kegan Paul, London 